\title{
Seroprevalence of HBsAg//HIV among Pregnant Women Attending State Hosiptal Antenatal Clinic, Ijebu-Ode
}

\author{
Omokayode Oluwafemi Emmanuel ${ }^{1 *}$, Ojiezeh Tony Ifeanyi ${ }^{2}$
}

${ }^{1}$ Department of Medical Laboratory Science, Achievers University, Owo, Ondo State, NIGERIA

${ }^{2}$ Department of Medical Laboratory Science, Afe Babalola University, Ado Ekiti, Ekiti State, NIGERIA

Email: gracephem@hotmail.com

\begin{abstract}
The rate of HBV and HIV infections in developing countries is alarming and may contribute to infant mortality. Therefore, there is a need to examine the prevalence of both infections among pregnant women, with an aim to determine the seroprevalence of HBV and HIV and rate of co - infection among pregnant women attending antenatal clinic at State Hospital, Ijebu-Ode, Nigeria. From 489 women attending antenatal clinic, individual serum was obtained and screened for HBV and HIV antibodies respectively using chromatographic immunoassay. Bio data, occupation, living conditions and parity was obtained using structured questionnaire. A total of 489 pregnant women within age 15 - 39-yearold were screened, HBV infection recorded $33(6.7 \%)$ while HIV was $20(4.1 \%)$. The duo was higher among 20 - 24 years age group: HBV 13(10.4\%) and HIV $9(7.2 \%)$, and co-infection was $2(0.004 \%)$. The incident of infections was higher among the artisans: HBV $20(8.0 \%)$ and HIV $9(3.6 \%)$ than others categories in relation about occupation. Increased frequency of HBV and HIV infections among pregnant women is alarming public health issues and should be given proper attention. The prevalence of the duo infections may be culpable in infant mortality, and complication following child birth for the mothers. Therefore, pregnant women should be screened for both HBV and HIV infections during antenatal care. Enlightenment campaign on the routes, modes of transmission and control measures should be step-up at antenatal clinics across the board.
\end{abstract}

Keywords: HBV, HIV, Prevalence, Antenatal care, Chromatographic immunoassay

\section{INTRODUCTION}

Infections with hepatitis B and human immunodeficiency viruses (HBV and HIV) are global public health problems, (Eke et al., 2011). Chronic hepatitis B is a spectrum of the disease usually depicted by the presence of hepatitis B surface antigen (HBsAg) in the blood/serum of an individual for longer than six months. Chronic hepatitis B may be inactive and cause no significant health problems, but may progress to liver fibrosis, cirrhosis, and hepatocellular carcinoma. The progression of liver disease is associated with HBV DNA levels in the blood

The risk of progression to chronic HBV infection is inversely proportional to the age at which the infection was acquired. Without any preventive measure, up to $90 \%$ of infants born to hepatitis B e antigen $(\mathrm{HBeAg})-$ positive mothers become infected. Only $20 \%$ to $30 \%$ of children exposed between ages 1 and 5 years, and fewer than $5 \%$ of adults, become infected,(McMahon et al., 1985 and Chang et al., 2000). Consequently, women of childbearing age remain the continued spread source of the virus (Natelie et al., 2010).

Developing countries such as Sub-Saharan Africa remains by far the most affected region, with 24.5 million people living with HIV, (Uneka et al., 2007). Research shows that HIV infection in pregnancy is associated with adverse maternal and fetal outcome, (Oladeinde et al., 2011) the effect of which includes among others infectious morbidity, 
vertical transmission, and severe anemia (Behets et al., 2008). Both HBV and HIV infections can be transmitted via unprotected sexual contact, unsafe blood transfusion, scarification with contaminated needles and instruments, and vertical transmission, amongst others (Olokoba et al., 2010, Adekanle et al., 2010 and Lassey et al., 2004) "mother-tochild-transmission" (MTCT) has been documented. Thus, the study on prevalence of HIV and HBV infections and, rate of co-infection among pregnant women receiving antenatal care at State Hospital, Ijebu-Ode area of Ogun State, southwestern part of Nigeria.

\section{MATERIALS AND METHODS}

\section{Study Area and Population}

The study was carried out among pregnant women attending State Hospital antenatal clinic, Ijebu-Ode and it has a warm tropical climate, it is on latitude $649^{\prime} 0.012$ " $\mathrm{N}$ and longitude $355^{\prime \prime} 59.988^{\prime \prime} \mathrm{E}$, with estimated population of 157,161 (2006 National Census). The study was carried out between October, 2014 and March, 2015 on four hundred and eighty nine (489) pregnant women, age 15 - 39 years, attending the antenatal clinic at State Hospital. The sample size for the study was calculated using the formula according to Araoye (Araoye et. al., 2003)). Consent of all participants was sought and only volunteers participated in the study.

\section{Collection, handling and processing of Specimens}

Venous blood samples were collected from each of the subjects and put in EDTA specimen containers for both HBV and HIV screening. Commercial HBsAg strips (ABON) and HIV Strips (Determine) were used in the study. The samples were spun at 5,000 rpm for 5 minutes, plasma extracted and screened for both HBsAg and HIV. In cases of HIV seropositive results, UniGold and Stat Pak were used for the double check. (Ethical clearance was obtained from the Ethical Committee of State Hospital, Ijebu-Ode, Ogun state).

\section{Methodology}

Serological method was employed here to determine the prevalence of HBV and HIV infections. Bio data, occupation, living condition and parity was obtained using questionnaire.

Results were read as:

Negative: No band in the test region (T), only one band appears in the control region (C).

Positive: The presence of the two bands lines on both test $(\mathrm{T})$ and control $(\mathrm{C})$ region indicates the presence of HBV or HIV antibodies.

Invalid: If no band appears in the control region (C), regardless of the presence or absence of a line in the test region (T). This indicates a possible error in the analytical stage. The test should be repeated.

\section{Statistical Analysis}

Data generated in this study were analyzed using the SPSS 16.0 software. The Chi-square test was used to determine statistical significance set at $\mathrm{P}<0.05$. The overall prevalence of $\mathrm{HCV}$ and $\mathrm{HBV}$ markers was expressed as the percentage of seropositive samples.

\section{RESULTS}

Table 1 depicted the distribution frequency of both HBV and HIV infections. 7.4\% of the entire subjects screened in age group 15-19years were HBV positive while 3.7\% were infected with HIV whereas $10.4 \%$ of 20 - 24 years age bracket were HBV seropositive while $7.2 \%$ were HIV seropositive. Similarly out of the population screened in the age group 25-29 years, $6.2 \%$ were HBV seropositive while 2.1\%were HIV infected. In age groups 30-34years $4.3 \%$ were infected with HBV and HIV respectively while in age groups 35 - 39years $4.3 \%$ were HVB seropositive and $2.9 \%$ were infected with HIV.

Table 1: Sero-distribution of HBV and HIV infections according to age

\begin{tabular}{|c|c|c|c|c|}
\hline Age group & No Examined & HBV Seropositive & HIV Seropositive & HIV/HBV Seronegative \\
\hline $15-19$ & 54 & $4(7.4 \%)$ & $2(3.7 \%)$ & $48(88.9 \%)$ \\
\hline $20-24$ & 125 & $13(10.4 \%)$ & $9(7.2 \%)$ & $103(82.4 \%)$ \\
\hline $25-29$ & 146 & $9(6.2 \%)$ & $3(2.1 \%)$ & $134(91.8 \%)$ \\
\hline $30-34$ & 94 & $4(4.3 \%)$ & $4(4.3 \%)$ & $86(91.5 \%)$ \\
\hline $35-39$ & 70 & $3(4.3 \%)$ & $2(2.9 \%)$ & $65(92.9 \%)$ \\
\hline Total & 489 & $33(6.7 \%)$ & $20(4.1 \%)$ & $436(89.2 \%)$ \\
\hline
\end{tabular}

$\mathrm{P}<0.05$ (significant at 0.05 ) 
KEY: HBV- Hepatitis B virus,

HIV - Human immunodeficiency virus

The distribution of HBV and HIV in relation about occupation is as shown in Table 2. Out of 29 subjects in schooling category 7(24.1\%) were HBV seropositive while $6(20.7 \%)$ were HIV sero-positive. Of 250 Artisan screened, 20(8.0\%) were HBV seropositive while $9(3.6 \%)$ were with HIV antibody. Of 210 subjects who were engaged in business and civil service $6(2.9 \%)$ were HBV seropositive and 5(2.4\%) were infected with HIV respectively.

Table 2: Distribution of HBV and HIV in relation about occupations

\begin{tabular}{|l|c|c|c|c|}
\hline Occupation & No Examined & HBV Seropositive & HIV Seropositive & HIV/HBV sera negative \\
\hline Student & 29 & $\mathbf{7}(24.1 \%)$ & $\mathbf{6}(20.7 \%)$ & $\mathbf{1 6 ( 5 5 . 2 \% )}$ \\
\hline Artisan & 250 & $\mathbf{2 0}(8.0 \%)$ & $\mathbf{9}(3.6 \%)$ & $\mathbf{2 2 1}(88.4 \%)$ \\
\hline Business \& & 210 & $\mathbf{6}(2.9 \%)$ & $\mathbf{5}(2.4 \%)$ & $199(94.8 \%)$ \\
\hline Civil Servant & & & & \\
\hline Total & 489 & $\mathbf{3 3}(6.7 \%)$ & $\mathbf{2 0}(4.1 \%)$ & $436(89.2 \%)$ \\
\hline
\end{tabular}

$\mathrm{P}<0.05$ (significant at 0.05 )

KEY: HBV- Hepatitis B virus,

HIV - Human immunodeficiency virus

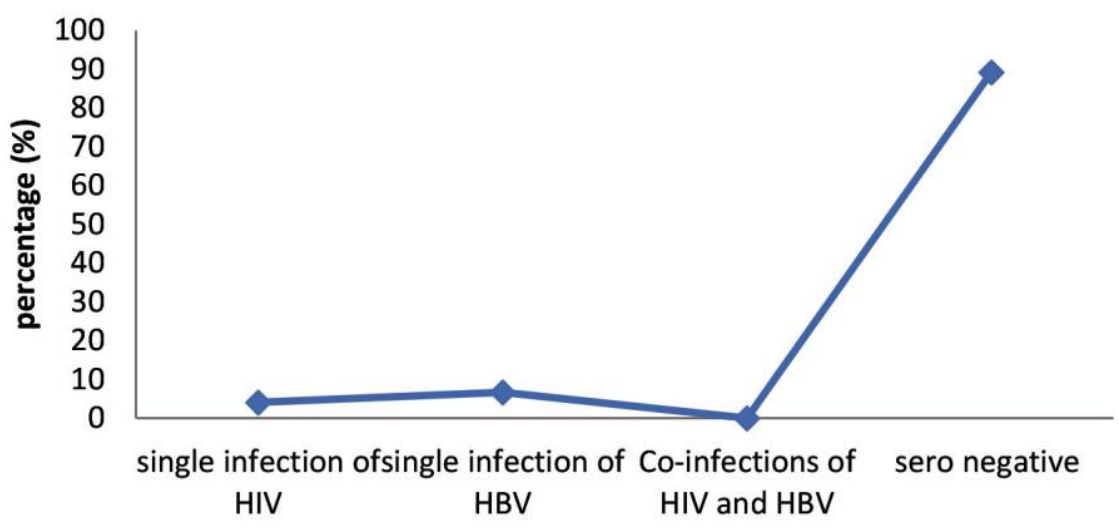

Figure 1: The frequency of infections of HIV and HBV among pregnant women attending antenatal clinics in ljebu-Ode

\section{Discussion}

The spread of HIV and HBV in developing countries is a public health concern, even in the sub-Sahara region. Our work was designed to elucidate the epidemiology of HIV and HBV in our community among pregnant women attending the antenatal clinic. Our result shows that there was a high occurrence of infection within the population studied. There seem to be a link between age and occupation in relation about pattern of infections. The youthful exuberant of the 20-24 year age group may also contribute to the higher frequency of infection. Our findings is in agreement with the reports of earlier workers in another part of Nigeria, indicating that there is increasing rate of infection of HIV in the nation and it should be looked into by government.

The report from Ijebu-Ode axis in Ogun State show a higher frequency of infection of HIV among pregnant women attending antenatal clinic when compared with the report from Amassoma in Bayelsa State (Egeise et al., 2008)) and Port Harcourt, River State (Buseri et al.,). But it was a lower frequency when compared with the reports from Abakaliki in Ebonyi State (Obi et al., 2005), Yola in Adamawa State (imade et al., 2004) and Akwa in Anambra State (Ezegbudo et al., 2004). The variation may not be unconnected to the differences in sexual practices and behavior, awareness of HIV infection and testing, Social -cultural practices and accessibility to healthcare services. The wide spread of the infection noticeable among child bearing age group in the country is worrisome. Therefore, the need for urgent action and concerted efforts to curb it spread. It is importance to note that aside age risk factor, is occupational risk factor. There was a statistically significant difference in the distribution of HBV sero-positive patients in relation to occupation $(\mathrm{P}<0.05)$. The incidence of HBV among child bearing age was higher in artisans than the students and working class. The artisans with little or no education had a higher frequency of infection of both HBV and HIV. It may be as a result of low esteem and the vulnerability to unprotected and unguarded sex. The 
level of awareness of HIV/HBV infections among them seem to be low, as most of them are semi literates who are either school dropout or have had informal trainings.

This study recorded less than $1 \%$ incidence of co-infection of HIV/HBV among the pregnant mothers; the rate is still low and should be kept low at all time, if not eradicated. The complications of health problems due to co-infections is usually severe, therefore, the need to put-in more efforts to stem the trend of the spread. The occurrence of coinfection should not be underestimated and should be taken seriously by all.

\section{Conclusion AND ReCOMmEndATIONS}

This study noted a moderate high prevalence of HBV and HIV infections amongst pregnant women in the study area. It is therefore recommended that pregnant women should be routinely screened for both HBV and HIV as part of their antenatal care services, and also interventions such as vaccines should be made available for seropositive mothers so as to prevent vertical transmission of these infections. However, government and non- governmental organizations should intensify efforts on enlightenment campaigns on the routes of transmission, modes of transmission, prevention and as well as acontrol measures of both infections in the locality and in the country at large.

\section{ACKNOWLEDGEMENT}

The authors wish to acknowledge the Medical Laboratory Scientists, Mr. O.M Lakunle, Mr. E. Oyeleye, Miss G.E Aiyeki, Mr. C.G. Onyewuenyi, Department of Medical Laboratory Science, State Hospital, Ijebu-Ode for their technical assistants

\section{CONFLICT OF INTERESTS}

The authors do not have a direct financial relationship with the commercial identity mentioned in this paper.

\section{REFERENCES}

Adekanle, O., Ndububa, D.A., Ayodeji, O. O., Paul-Odo, B., Folorunso, T. A. (2010), "Sexual transmission of the hepatitis B virus among blood donors in a tertiary hospital in Nigeria", Singapore Med J, 51:944-7.

Araoye, M.O. (2003), "Sample size determination. In Margaret OA, editor. Research methodology with statistics for health and Social Sciences, Ilorin, Nigeria," Nathadex Publishers, Pp 115 -119.

Behets, F. I., Matendo, R., Vaz, M. E., Kilese, N., Nanlele, D., Kokolomami, J. (2008), “Preventing vertical transmission of HIV in Kinshasa, Democratic Republic of the Congo: A baseline survey of 18 antenatal clinics," Bull World Health Organ, 24:969-75.

Buseri, F. I., Jeremiah, Z. A., Erhabor, O. (2008), "Prevalence of HIV seropositivity among antenatal women in Port Harcourt," Trop J Health Sci, 15:55-60.

Chang, M. H. (2000), "Natural history of hepatitis B virus infection in children”, J Gastroenterol Hepatol, 15 (Suppl): E16-E19.

Egesie, U.G., Mbooh,. R. T. (2008), “Seroprevalence of human immunodeficiency virus (HIV) infection in pregnant women in Amassoma," Nigeria Afr J Biomed Res, 11: 111-3.

Eke, A. C., Eke, U. A., Okafor, C. I., Ezebielu, I. U. (2011), "Prevalence correlates and pattern of hepatitis B surface antigen in a low resource setting", Virol J, 8:12.

Ezegbudo, C. N., Agbonlahor, D. E., Nwobu, G.O., Igwe, C. U., Agba, M.I., Okpala, H.O. (2004), “The seroprevalence of hepatitis B surface antigen and human immunodeficiency virus among pregnant women in Anambra State, Nigeria", Shiraz E-Med J, 5:1-9.

Imade, G. E., Sagay, A. S., Ugwu, B, Thacher, T. D., Ford, P. W. (2004), "Seroprevalence of hepatitis B and HIV infections in pregnant women in Nigeria," J Med Trop, 6: 15-21.

Lassey, A. T., Damale, N. K., Bekoe, V., Klufio, C. A. (2004), “Hepatitis C seroprevalence among mothers delivering at the Korle - Bu Teaching Hospital, Ghana," E Afr Med J, 8:198-201.

McMahon, B. J., Alward, W. L., Hall, D. B, et al. (1985), "Acute hepatitis B virus infection: relation to the clinical expression of disease and subsequent development of the carrier state", J Infect Dis, 151: 599-603.

Natalie H. Bzowe (2010), "Hepatitis B Therapy in Pregnancy". Curr Hepat Rep. 9(4): 197-204.

Obi, S. N. (2005), "Pregnant outcome in HIV seropositive women in Abakaliki, Nigeria", Orient J Med, 17: 25-30.

Oladeinde, B. H., Omoregie, R., Olley, M., et al. (2011), "Prevalence of HIV and anemia among pregnant women", North Am J Med Sci, 3: 548-51.

Olokoba, A. B., Tidi, S. K., Salawu, F. K., Danburam, A., Desalu, O. O., Abdurrahman, M. B. (2010), “Human immunodeficiency virus infection in voluntary blood donors in North-Eastern Nigeria", Am J Sci Indian Res, 1: 435-8.

Tassopoulos N. C., Papavangelou, G. J., Sjogren, M. H., et al. (1987), Natural history of acute hepatitis B surface antigen-positive hepatitis in Greek adults, Gastroenterology, 92: 1844-1850.

Uneka, C. J., Duhlinska, D. D., et al. (2007), "Prevalence and public health significance of HIV infection and anaemia among pregnant women attending antenatal clinics in Southern Nigeria," J Health Popul Nutr, 25:328-35.

$$
\text { -- } 0 \text {-- }
$$

